\title{
Towards a Thermal Characterization of a Firefighter's Protective Clothing
}

\author{
S. DAHAMNI*, A. BENAROUS**, P. A. G. PILOTO*** \\ *CEMSM Laboratory, University Hassiba Benbouali of Chlef, Esalem City, 02000 Chlef, Algeria, \\ E-mail: s.dahamni@univ-chlef.dz. \\ **University Saad Dahlab, Soumaa Road,09000,Blida, Algeria, E-mail: abenarous@yahoo.fr \\ ***Polytechnic Institute of Bragança (IPB), Campus Santa Apolónia, 5301-857 Bragança, Portugal, \\ E-mail: ppiloto@ipb.pt
}

cross $^{\text {ref }}$ http://dx.doi.org/10.5755/j01.mech.26.5.22532

\section{Nomenclature}

$C_{P}$ is specific heat, $\mathrm{J} / \mathrm{kg} . \mathrm{K} ; h_{C 1}$ is convective heat transfer exchange with the surrounding environment coefficient, $\mathrm{W} / \mathrm{m}^{2} . \mathrm{K} ; h_{C}$ is convective heat coefficient between skin surface and surrounding air (moisture), $\mathrm{W} / \mathrm{m}^{2} . \mathrm{K} ; h_{r}$ is radiative heat transfer coefficient, $\mathrm{W} / \mathrm{m}^{2} . \mathrm{K} ; H R_{\text {air }}$ is relative humidity, $\% ; P_{\text {sat }}$ is water vapor pressure, $\mathrm{kPa} ; Q_{\text {ech }}$ is net flux exchanged between the epidermis and the back face of the layer $\mathrm{C} 3, \mathrm{~W} / \mathrm{m}^{2} ; q$ is metabolic heat generation, $\mathrm{W} / \mathrm{m}^{3} ; q_{r}$ is radiative heat flux received from the pool fire, $\mathrm{W} / \mathrm{m}^{2} ; T$ is temperature, ${ }^{\circ} \mathrm{C}, \mathrm{K} ; w_{b l}$ is blood perfusion rate, $\mathrm{s}^{-1} ; w_{s}$ moisture content, $\%$

Greek symbols. $\alpha$ is absorption coefficient; $\delta$ is thickness, $\mathrm{mm}$; $\varepsilon$ is emissivity coefficient; $\lambda$ is thermal conductivity, $\mathrm{W} / \mathrm{m} . \mathrm{K} ; \rho$ is density, $\mathrm{kg} / \mathrm{m}^{3}$

Subscripts. amb is ambient; $b l$ is blood; $C$ is convective; $C 1$ is first layer of the garment; $E$ is epidermis; ext is far-field; metb is metabolism; $\min$ is minute; $r$ is radiative; Skin; sat is saturation.

\section{Introduction}

Improving the performances of a firefighter clothing require a good understanding of the thermal exchanges between the clothing and the ambient surrounding as well as the firefighter's body. Indeed, early modelling and experimental investigations have revealed the importance of the skin biothermics that should account for sudation and organism thermoregulation [1]. On the other hand, recent firefighter clothing technologies have evidenced the multilayered configuration of the textile, which have to be separated by several air-gaps to enhance the thermal resistance [2]. A concise analysis on the characterization of multilayer fabrics has highlighted the contribution of convective, radiative and conductive thermal exchanges within the clothingbody assembly [3]. Accordingly, the net incoming heat fluxes to the skin should be kept at low values to avoid the burning injury threshold. In this direction, some authors have concluded that thermal insulation of the skin can be enhanced by an increase in the thickness of the fabrics, but the lightness of the clothing was not considered [4]. In the aim to promote the conductive heat transfer mode, Wang et al. [5] focused on the interlayer space where the air gap contributes to enhance the thermal resistance. They concluded that the air-gap can be considered as a significant shielding layer that can absorb a major part of the heat fluxes emitted and transferred by the fabrics. Ghazy et al. [6] were interested in the quantification of the radiative heat fluxes within the fabrics layer. The major finding of their study was that a change in the external layer emissivity of the fabrics can strongly affect the thermal insulation of the skin. Accordingly, Collin et al. [7] have conducted an experimental campaign on the radiative heat exchanges between the fabrics and its surrounding, including the flame pool. Their research reported that the far-field temperature level is of a great importance in the thermal balance on the fabric's first layer. For engineering purposes, Mandal et al. [8] succeed in developing an empirical model for the temperature distribution across the fabrics thickness. The authors performed several tests on manikins subjected to instationnary incoming fluxes, without accounting for biothermics. The same authors focused on the fabrics characteristics, namely the weight and the number of layers and stated concludingly that an optimization study using neural network technique (ANN) can improve fabrics manufacturing processes [9]. Some recent studies have shown the importance of accounting for both conduction and radiation in each air-gap that separates two adjacent fabrics layers [10]. In their investigation, thermal conductivity of each fabrics and air layer was considered as a temperature-dependent quantity in the Fourier equation.

In the present work, one attempts to reproduce the thermal behaviour of a firefighter protective clothing and to evaluate its influence on the burning injury of the skin layer. A one-dimensional model featuring several fabrics and skin layers is developed. Coupled heat transfer modes including convection, radiation and conduction are considered, with temperature dependent conductivity for air-gap layers. A preliminary calculation without all biological layers is undertaken to tune thermophysical parameters in a manner to reproduce the equilibrium temperature distribution obtained by a full-2D simulation [11], as well as the transient temperature of the first skin layer as recovered by Collin et al. [7]. The investigation is completed with a parametric analysis including possible fluctuations of both ambient temperature and fabrics external absorptivity. Governing equations are solved in a finite element (FE) formulation using Comsol Multiphysics $^{\circledR}$, associated with the surface-to-surface (S2S) radiative model.

\section{Heat transfer modelling}

Owing to length scale ratio of the garment configuration, a one-dimensional formulation is adopted for the 
heat transfer governing equations. In the following, convective heat fluxes within fabrics layers are neglected on a basis of the sensitivity analysis made by Benchabi et al. [12]. In fact, coupled convective-radiative heat transfers are considered for the external side of the garment, as well as for the third air-gap located at the fabrics-skin interface (Fig. 1). As sketched in Fig. 1 the garment features three fabrics layers (C1, C2, C3) separated by three air-gaps. According to the works of Collin et al. [13], the skin is modelled as conductive media, with five adjacent layers; namely epidermis (E), dermis (D), hypodermis (H), muscles (M) and bone (B). At the skin left side, thermal energy is transferred through radiation from the protective clothing and conduction from the air-gap. The energy is therefore conducted through five layers of human skin to the right boundary that stands for the metabolism.

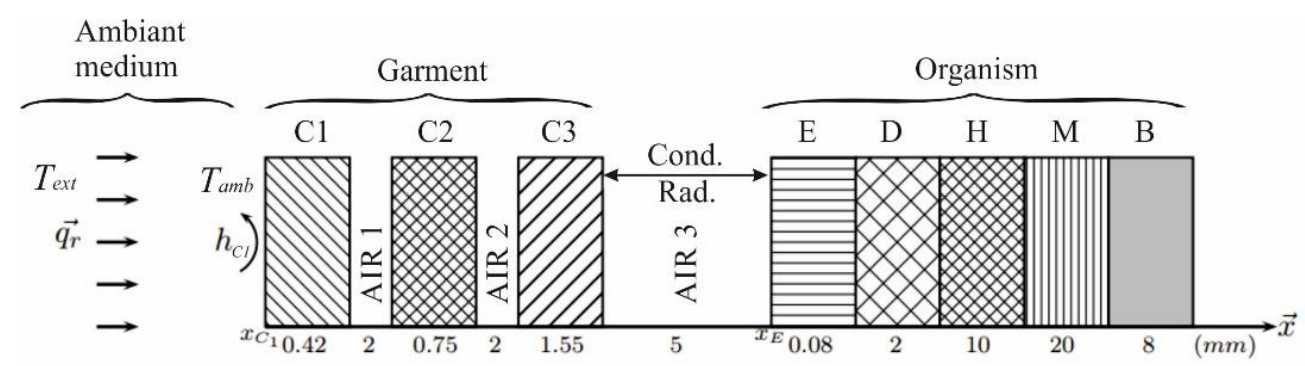

Fig. 1 1-D Domain sketch of the garment-skin assembly

\subsection{Heat transfer in the clothing}

The clothing is modelled as a multilayer media, featuring a self-extinguishing aramid layer (C1), a waterproof breathable layer $(\mathrm{C} 2)$ and a liner that provides thermal protection for the firefighter (C3) and ensures a thermal comfort for the body. The balance equation for the coupled convection-radiation heat exchange between the first layer (C1) and the ambient medium can be written as:

$-\left.\lambda_{C 1} \frac{\partial T}{\partial x}\right|_{x=x_{C 1}}=\left(h_{C 1}+h_{r}\right)\left[T_{a m b}-T\left(x_{C 1}, t\right)\right]+\alpha_{C 1} q_{r}$,

where:

$$
h_{r}=\sigma \alpha_{C 1}\left(T_{e x t}^{2}+T^{2}\left(x_{C 1}, t\right)\right)\left(T_{e x t}+T\left(x_{C 1}, t\right)\right),
$$

$h_{r}$ stands for the equivalent radiative exchange coefficient of the first layer (C1). $h_{C 1}, \alpha_{C 1}, \varepsilon_{C 1}$ denote respectively for the convective exchange coefficient with the ambient medium, the absorption coefficient and the emissivity coefficient of the layer $(\mathrm{C} 1)$. The incoming flux $q_{r}$ stands for the radiative fraction of the heat release rate, and assumed to represent $80 \%$ from the global flux at the fire source [13, 14]. Within each tissue layer (Ci) the conductive transfer is governed by the Fourier equation [15]:

$$
\rho_{C i} C p_{C i} \frac{\partial T\left(x_{C i}, t\right)}{\partial t}=\lambda_{C i} \frac{\partial^{2} T\left(x_{C i}, t\right)}{\partial x^{2}} ; \quad i=\overline{1,2,3},
$$

where: $\rho_{C i}, C p_{C i}, \lambda_{i}$ denote respectively, the density, the specific heat and the thermal conductivity of the layer's fabric, and are seemed to be uniform within each layer. Moreover, the thermal conductive flux across the air-gap obeys the Fourier law, with temperature-dependent properties, as [15]:

$$
\frac{\partial T_{a i r_{i}}(x, t)}{\partial t}=D_{a i r_{i}} \frac{\partial^{2} T_{a i r_{i}}(x, t)}{\partial x^{2}} ; \quad i=\overline{1,2,3},
$$

where: $D_{a i_{i}}=\lambda_{\text {air }}\left(T_{a i r_{i}}\right) / \rho_{a i i_{i}}\left(T_{a i_{i}}\right) C p\left(T_{a i_{i}}\right)$ stands for the

thermal diffusivity of the $i^{\text {th }}$ air-gap layer. The radiative net flux exchanged between two adjacent tissue layers $(\mathrm{Ci}, \mathrm{Cj})$, can be expressed as [15]:

$$
\Phi_{i \rightarrow j}=\sigma \varepsilon_{i j}\left[T^{4}\left(x_{C i}, t\right)-T^{4}\left(x_{C j}, t\right)\right],
$$

where: $\sigma=5.670367 \times 10^{-8} \mathrm{~W} / \mathrm{m}^{2} \cdot \mathrm{K}^{4}$ is the Stefan-Boltzmann constant and $\varepsilon_{i j}$ is the equivalent emissivity, which can be written for a case of two parallel infinite surfaces, as [16]:

$$
1 / \varepsilon_{i j}=1 / \varepsilon_{i}+1 / \varepsilon_{j}-1 \text {. }
$$

Since convective transfer is neglected in the layer/air-gap $\left(C_{i}, a i r_{i}\right)$ interface, the total flux conservation, can be written as [6]:

$$
\begin{aligned}
& -\left.\lambda_{C i} \frac{\partial T}{\partial x}\right|_{x=x_{C i}}=-\left.\lambda_{a i i_{i}}\left(T_{a i_{i}}\right) \frac{\partial T}{\partial x}\right|_{x=x_{a i r_{i}}}+ \\
& +\sigma \varepsilon_{i j}\left[T^{4}\left(x_{C i}, t\right)-T^{4}\left(x_{C j}, t\right)\right],
\end{aligned}
$$

$i=\overline{1,2}$ and $j=i+1$.

For this case, the incoming fluxes $q_{r}$ is included in the balance equation for the first fabrics layer $(\mathrm{C} 1)$, whereas a convective boundary condition is considered on the left side of the first skin layer (Fig. 2).

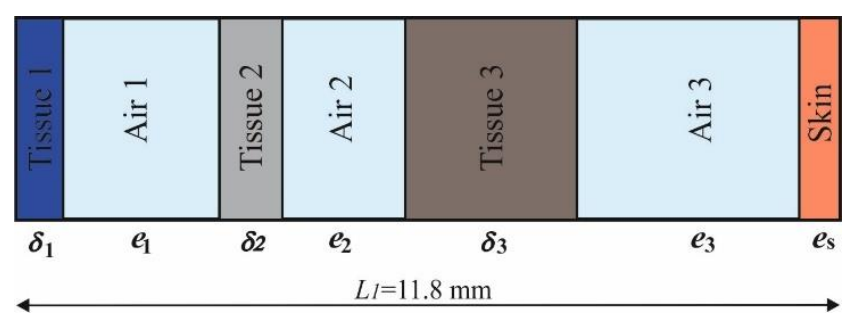

Fig. 2 Calculation domain 


\subsection{Heat transfer within the skin}

According to the works of Pennes in 1948, an adaptation of the Fourier equation considers the metabolism heat generation as well as the blood circulaction as key phenomena in the biothermal transfer. The corresponding conduction equation have the following form [1]:

$$
\begin{aligned}
& \rho_{\text {Skin }} C p_{\text {Skin }} \frac{\partial T(x, t)}{\partial t}=\lambda_{\text {Skin }} \frac{\partial^{2} T(x, t)}{\partial x^{2}}+q_{\text {metb }}+ \\
& +w_{b l}\left(C_{b l} \rho_{b l}\right)\left[T_{a r t}-T(x, t)\right], \quad x \geq x_{E} . \\
& -\left.\lambda_{E} \frac{\partial T(x, t)}{\partial t}\right|_{x=x_{E}}=-\left(3.054+16.7 h_{C} w_{s}\right)+\left(P_{s a t}\left(T_{x_{E}}\right)-H R_{a i r} P_{s a t}\left(T_{a i r 3}\right)\right)+Q_{e c h},
\end{aligned}
$$

where: $\rho_{S k i n}, C p_{S k i n}, \lambda_{S k i n}$ and $q_{\text {metb }}$ denote respectively, the density, the calorific capacity, the thermal conductivity and the rate of metabolic heat production per unit volume of tissue. $w_{b l}, C_{b l}$ and $\rho_{b l}$ represent the perfusion rate per unit volume of tissue, the blood calorific capacity and density. The artery temperature of blood is believed to be maintained at a constant value, $T_{a r t}=36.8^{\circ} \mathrm{C}$. As for the garment layers, thermal flux continuity is considered at each biologic layer interface, except for the Air3 layer where a convectiveevaporative condition is imposed, to account for sweating phenomenon. Accordingly, the condition is written as [17]: where:

$Q_{\text {ech }}=-\left.\lambda_{\text {air }} \frac{\partial T(x, t)}{\partial x}\right|_{x=x_{E / \text { air }}}+\sigma \varepsilon_{\text {Skin }}\left[T^{4}\left(x_{C 3}, t\right)-T^{4}\left(x_{E}, t\right)\right]$.

$Q_{\text {ech }}$ is the net flux exchanged between the epidermis and the back surface of the C3 layer [13]. A Dirichlet condition $T_{a r t}=36.8^{\circ} \mathrm{C}$ is imposed on the right side of the last skin layer, and it stands for the metabolism's thermal regulation.

\section{Thermophysical properties}

As commonly used for conjugated analysis in engineering, one attempts to mimic conductive heat transfer within the skin layers using a domain truncation [10], (Fig. 2). Here, the model considers a single skin layer with the same Epidermis thickness $\left(e_{s}=0.08 \mathrm{~mm}\right)$, while featuring average values for the thermophysical properties (Table
1). The averaging has been performed upon all the skin layers' properties (E, D, H, M) in a manner to recover the same thermal resistance [11]. The metabolism contribution is therefore highlighted throughout the convective evaporative Eq. (9) at the skin-air3 interface, and via the Dirichlet condition $T_{\text {art }}=36.8^{\circ} \mathrm{C}$.

Table 1 depicts the thermophysical properties of the fabrics layer according to the measurement campaigning made by Collin et al. [7]. As mentioned above, the average values for the skin properties were implemented in the COMSOL material database solver. Obviously, these values cannot be suitable for situations where heat stress occurs. Indeed, thermal stress is a phenomenon where heat fluxes develop simultaneously in opposite directions, i.e., from the firefighter surrounding to the skin and from the skin surface towards the clothing layers. Here, heat may be trapped within the clothing, inducing therefore important fluctuations on the thermophysical properties [18]

Fabrics-Skin assembly properties [7]

\begin{tabular}{|c|c|c|c|c|c|c|c|}
\cline { 2 - 7 } \multicolumn{1}{c|}{} & $\begin{array}{c}\text { Thickness } \\
\delta, \mathrm{mm}\end{array}$ & $\begin{array}{c}\text { Thermal conductivity } \\
\lambda, \mathrm{W} / \mathrm{m} . \mathrm{K}\end{array}$ & $\begin{array}{c}\text { Density } \\
\rho, \mathrm{kg} / \mathrm{m}^{3}\end{array}$ & $\begin{array}{c}\text { Specific heat } \\
C p, \mathrm{~J} / \mathrm{kg} . \mathrm{K}\end{array}$ & $\begin{array}{c}\text { Emissivity } \\
\varepsilon\end{array}$ & $\begin{array}{c}\text { Perfusion rate } \\
w_{b l}, \mathrm{~s}^{-1}\end{array}$ & $\begin{array}{c}\text { Metabolic heat } \\
\text { generation } \\
q, \mathrm{~W} / \mathrm{m}^{3}\end{array}$ \\
\hline $\mathrm{C} 1$ & 0.42 & 0.081 & 605.0 & 1187.5 & 0.60 & - & - \\
\hline C2 & 0.75 & 0.041 & 212.0 & 1297.0 & 0.60 & - & - \\
\hline C3 & 1.55 & 0.038 & 112.0 & 1219.0 & 0.60 & - & - \\
\hline Skin & 0.08 & 0.37 & 1200.0 & 3590.0 & 0.98 & 0.00185 & 380.5 \\
\hline
\end{tabular}

As convection manifests on both sides of the fabric layers, a value of $8 \mathrm{~W} / \mathrm{m}^{2} . \mathrm{K}$ is adopted for the convective transfer coefficient between the first layer and the ambient air. An average value of $4 \mathrm{~W} / \mathrm{m}^{2} . \mathrm{K}$ is taken to characterize the convection between the skin surface and the $\mathrm{C} 3$ layer. The adopted value $2.3 \mathrm{~kW} / \mathrm{m}^{2}$ of the incoming heat flux from the fire source corresponds to a stationary situation that mimics the average level of exposure of firefighters during standard semi-confined fires [13].

\section{Results and discussions}

The developed coupled partial differential equations (PDE's) were solved using the finite element method, by means of the COMSOL Multiphysics ${ }^{\circledR}$ software. This is a powerful environment for modelling and solving a variety of engineering and research problems. It is particularly suit- able for coupled heat transfers, featuring conjugated boundary conditions. The solver was successfully tested and validated, earlier, for a 2-D case [11]. In a such resolution, a structured and non-uniform grid of 165000 quadrilateral elements, was retained for the simulation, after a temperature sensitivity analysis (relative deviation of less than of 5\%) on finer grids. The time step was automatically adapted in the solver, according to the local grid size and the target courant number $(C F L=0.98)$. As thermal equilibrium is believed to be reached in the absence of heat-stress phenomenon, a stationary calculation was performed on the computational domain, deprived from skin sub layers (Fig. 2). Nevertheless, average thermophysical properties were used for the skin like domain -considered as a single layer-for which conduction occurred under a Dirichlet condition at its right boundary. 
In the present case (1D), situation, the numerical profile for the temperature across the fabrics thickness is depicted in Fig. 3. The reported values seem fairly close to those provided throught a full-2D calculation [11]. This behavior further confirm that heat fluxes develop mainly in the thickness direction (1D).

Here, the external surface of the garment is at a fairly high temperature $\left(\sim 126^{\circ} \mathrm{C}\right)$ despite the low value of $\mathrm{C} 1$ layer absorptivity. A significant decrease in temperature is noticed inside the C1-Air1 assembly where the thermal level is close to $107^{\circ} \mathrm{C}$ (Fig. 3).

The previous finite element calculations were performed on a 2D domain, having the same thickness as for the present $1 \mathrm{D}$ domain, where the height was equivalent to that of a firefighter's garment [11]. Owing to lack of thermal data, the fabrics were assumed to be homogeneous in terms of thermal conductivity. This property was supposed to develop identically in both axial and vertical directions, imposing therefore an equal thermal diffusion in these directions. The adopted assumption may not affect strongly the temperature distribution in the full-2D analysis, since the isotropy on the thermal conductivity can be ensured up to $95 \%[16]$.

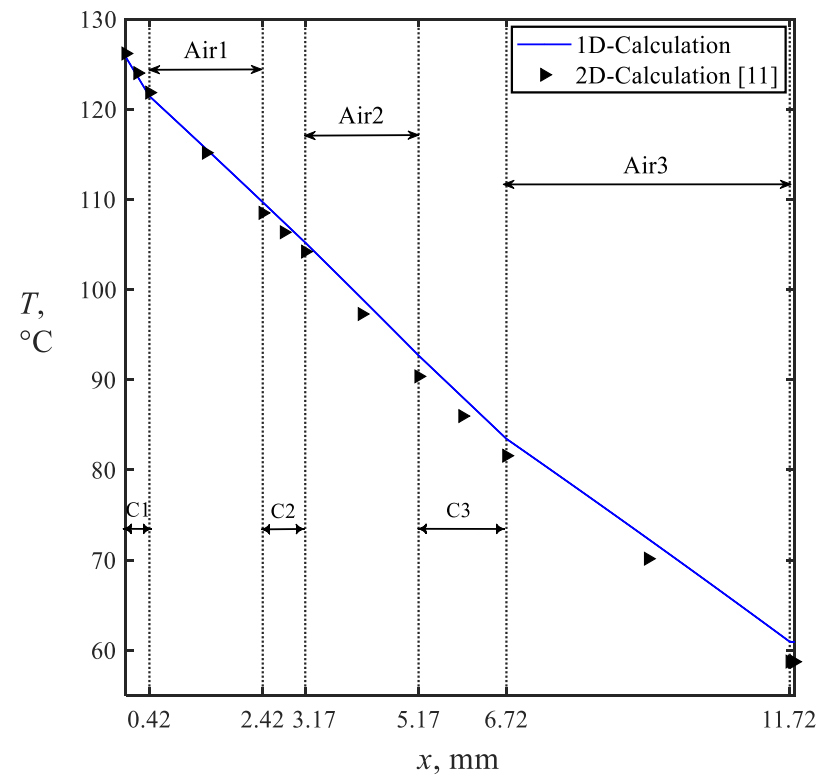

Fig. 3 Temperature profile through the thickness of the garment

Particularly, the decay of the temperature is more pronounced in the air-gap interface, where the thermal resistance is important. The temperature continues it decreasing to reach a value close to $T=60^{\circ} \mathrm{C}$ which seems fairly consistent with the 2D-calculations [11]. For this stationnary situation, one attempts to build polynomial expressions for the temperature distribution, that are strongly useful in off-design projets of firefighter garments [8]. Fig. 4 depicts the picewise-polynomial expressions, revealing linear decays with different slopes. It is worthy noticed that important slopes occur in the air-gaps where air conductivity and gap thickness contribute to enhance the thermal insulation.

For the following case, a study is performed under thermal equilibrium. Here, the stationnary calculation concerns the full computational domain (Fig. 1), accounting for skin layers and skin properties. The figure below (Fig. 5) depicts the temperature evolution across the clothing within the skin layers. The numerical results are compared to the stationnary distribution provided by Collin et al. [13].

Within the clothing, the numerical distribution of the temperature is quite close to the finite-volume based results [13]. A slight overestimation up to $4 \%$ is noticed on the F. E-based value of the skin temperature. This discrepancy is mainly due to the average values of the skin properties used in the present simulation and not reported in the work of Collin et al. [13]. Both temperatures evolution through the skin layers are quite similar, except in the Epidermis, where F.E values are slightly greater $(\sim 6 \%)$ compared to those of Collin et al. [13]. Indeed, owing to the uncertainly data related to perfusion rate and metabolic heat generation, the finite volume calculations were conducted with zero values $\left(w_{b l}=0, q_{\text {metb }}=0\right)$, which obviously affect the local (Epidermis) heat flux balance.

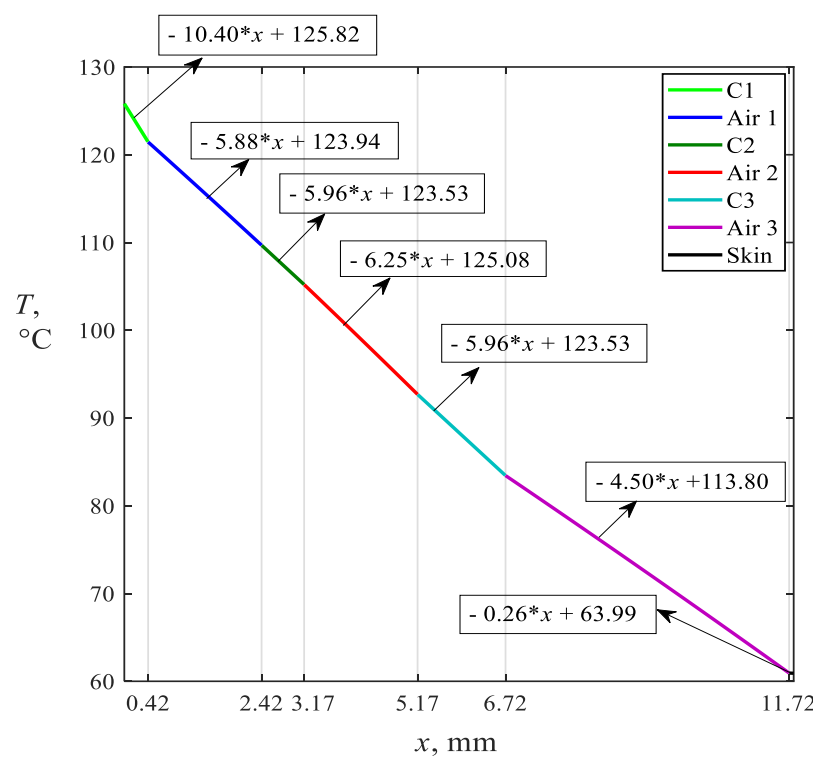

Fig. 4 Piecewise-polynomials for temperature across the clothing thickness

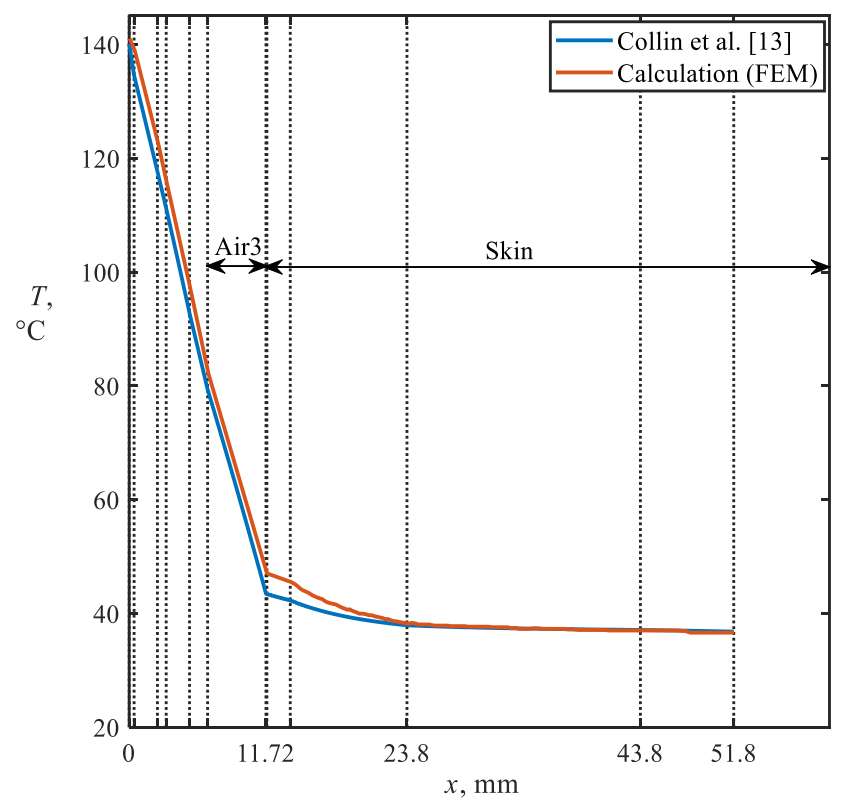

Fig. 5 Stationary temperature distribution

Despite the steadiness of the incoming heat flux $q_{r}$, 
an unsteady behavior is noticed on temperature evolution at the skin surface. Indeed, a thermal accumulation is believed to occur within the garment-skin interface, namely in the air3 gap. Here, a focus is made on the E/D interface that is located at $x=11.8 \mathrm{~mm}$, where the first skin injury begins beyond $44^{\circ} \mathrm{C}[10]$.

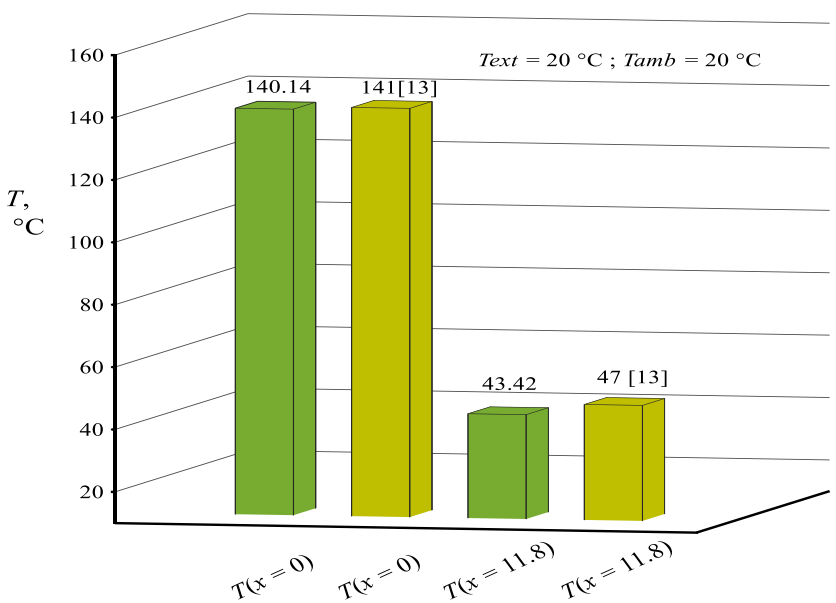

Fig. 6 Temperature of the outer layer $(x=0 \mathrm{~mm})$ and the epidermis/dermis interface histogram $\left(T_{E / D}\right)$ $(x=11.8 \mathrm{~mm})$

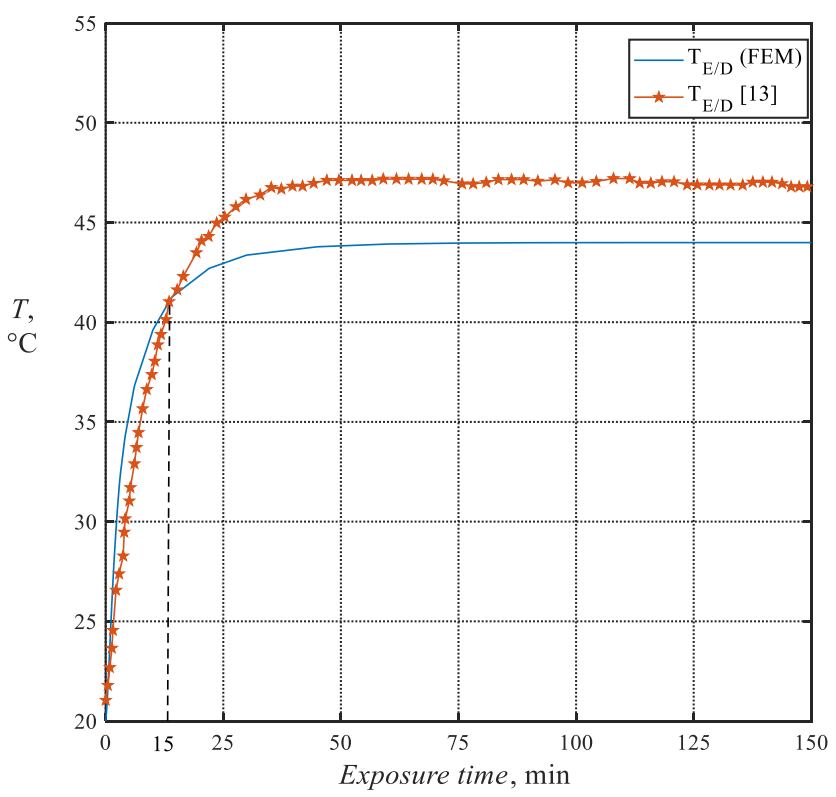

Fig. 7 Temperature evolution at E/D interface

Fig. 7 depicts the temperature evolution at E/D interface, for an important exposure time. The finite volumebased values [13] seem close to the numerical temperature profile in the range [0,15 minutes]. The slight overestimation noticed on the F.E.M-based values is mainly related to metabolism heat absorption occurring in the full-transient step of the garment-body interaction. Beyond 15 minutes of exposure, skin temperature exceeds $40^{\circ} \mathrm{C}$ and the rate of temperature evolution decreases up to 25 minutes, where it vanishes revealing therefore, a thermal steady state. The F.E-based profile of the temperature recovers a stationary state, that may be considered as a quite safe situation, with regards to skin injury limits. Despite a concise representation of all the skin layers, the F.V-based model recovers a steady state above the thermal threshold of $44^{\circ} \mathrm{C}$ [13]. Consequently, the performance of the finite volume analysis seems questionable, since the adopted properties of the fabrics correspond to a currently-used firefighter clothing. It is also important to stress that the uncertainties noticed on thermophysical properties of garment tissues, can be related to separate measurements techniques as well as possible fluctuations during interventions [20]. In the following, one attempts to predict temperature evolution across the clothing if the external layer (C1) is subjected to absorptivity fluctuation. Indeed, radiative clothing properties, namely absorptivity $\alpha_{C 1}$ may change owing to dye loss or cluster deposition and affect therefore, the local thermal balance. Fig. 8. shows curves of temperature evolution for several C1-layer absorptivities. Here, the radiative reflectivity was not considered and the adopted absorptivity range was provided according to the characterization campaign led by Collin et al. [7].

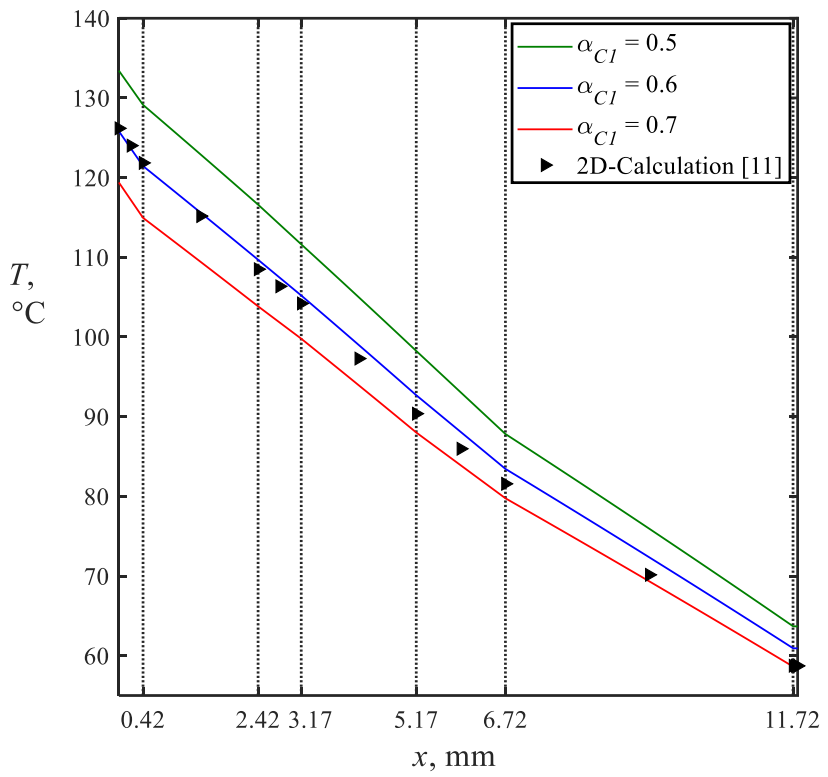

Fig. 8 Temperature evolution for different absorptivities of the first fabrics layer $(\mathrm{C} 1)$

Since reflectibility is not considered in this study, improving the absorptivity will obviously lead to a transmissivity diminution. Consequently, the fraction of the heat flux transmitted across the garment layers is less important and the first skin layer is more insulated. Indeed, temperature profile for $\alpha_{c 1}=0.7 \mathrm{~mm}$ exhibits more flatness except within the C1-layer where it changes significantly (Fig. 8). The relative decrease of the Epidermis temperature $(x=11.72 \mathrm{~mm})$ is close to $7 \%$. It should be noted that in the standard configuration, temperatures used to characterize the air adjacent to layer $\mathrm{C} 1 \quad\left(T_{a m b}\right)$ and the external environment consisting of smoke $\left(T_{e x t}\right)$ were all considered equal $T_{a m b}=T_{e x t}=20^{\circ} \mathrm{C}$. These values were chosen to mimic the finite volume calculations performed by Collin et al. [13]. In a flashover situation, the air surrounding the firefighter can become very hot, reaching a value of $T_{a m b}=200^{\circ} \mathrm{C}$; while the far atmosphere of the fighter can be slightly heated due to the smoke diffusion and the fresh air entrainment $\left(T_{e x t}=60^{\circ} \mathrm{C}\right)$. These two situations are sketched in Fig. 9.

Fig. 9 shows the thermal level on both first fabrics (C1) and skin (E/D) layers for situations where far-field air temperature rises to $60^{\circ} \mathrm{C}$, and near-field smoke temperature is at $200^{\circ} \mathrm{C}$, respectively. It is clearly shown that for a given 
abosorptivity of the first garment layer (C1), an increase in external or ambient thermal conditions, will be in favour on its exposure rate, since temperature difference $\Delta T_{C 1 \text {-amblext }}$, is believed to decrease. Moreover, the same external conditions contribute to enhance the thermal insulation of body skin. This statement should be taken with care, since heat stress that acts, as an antagonist heat evacuation phenomenon, is not considered in the present study.

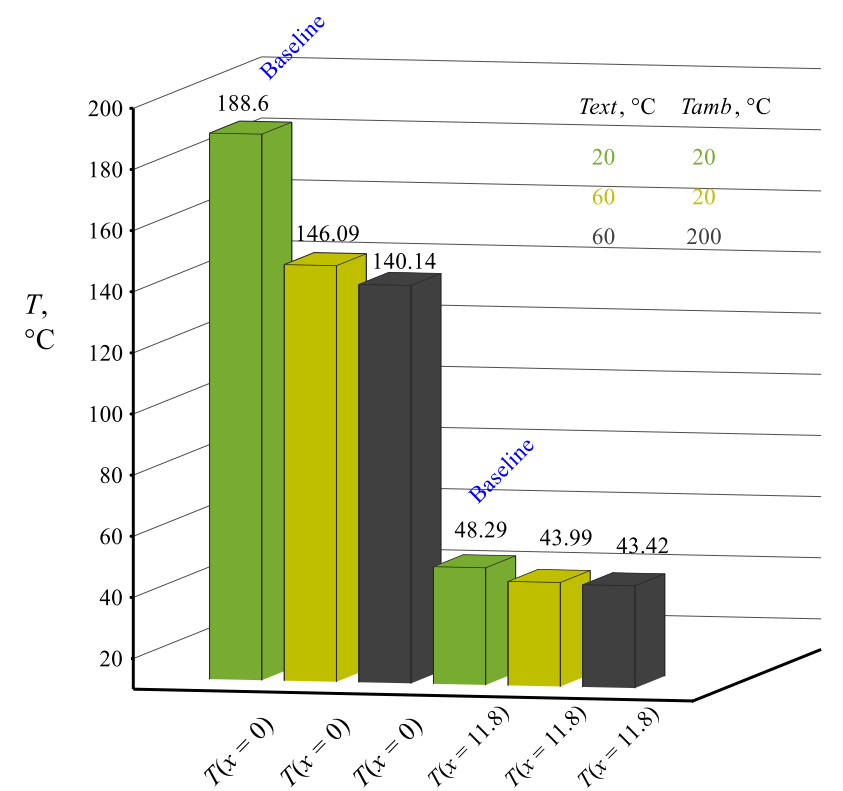

Fig. 9 Temperature level $\left(T_{E / D}, T_{C 1}\right)$ histogram for several ambient conditions

\section{Conclusions}

The present investigation was devoted to the thermal analysis of a clothing-skin assembly for a firefighter during a standard intervention. Based on previous 2-D computation and confirmed by several literature statements, a one-dimensional finite element (F.E) heat transfer model was developed and implemented in the COMSOL Multiphysics solver.

Multiple types of boundary conditions, including Dirichlet, convective-radiative and convective-evaporative relations were considered in accordance to the local coupling of heat transfer phenomena. The temperature profile across the clothing thickness was numerically predicted and successfully compared to the full-2D distribution. To contribute to the development of future numerical tools for fabrics characterization, the decay temperature curve was fitted using pricewise-polynomials which are related to the thermophysical properties of both air gaps and garment layers. In the stationary regime, the temperature profile across the clothing thickness was fairly close to the finite-volume based distribution, as recovered by the team of Collin et al. [13]. The finite element model succeeded in recovering a thermal relaxation at the skin surface, featuring therefore a steady state after $25 \mathrm{~min}$ of fire exposure. Furthermore, the adopted average values for the skin thermophysical properties seemed suitable for preserving a thermal level below the burning injury limit. Further modelling and numerical simulations are needed to deal with possible reverse heat fluxes (heat stress) across the clothing as well as evaporation/condensation (sweating) at the skin surface. These challenging tasks are currently under investigation and will be provided in a future work.

\section{Acknowledgements}

The present work is funded by the Algerian research organism DGRSDT, under project No. A11N01UN020120150001.

\section{References}

1. Pennes, H. H. 1948. Analysis of tissue and arterial blood temperatures in resting human forearm, Journal of Applied Physiology 1: 93-122. https://doi.org/10.1152/jappl.1998.85.1.5.

2. DiNenno, P. J. 2002. SFPE handbook of fire protection engineering, third edition (3rd ed.). Quincy, Mass: Bethesda, Md.: National Fire Protection Association; Society of Fire Protection Engineers. USA. 1604 p.

3. Torvi, D. A.; Dale, J. D. 1999. Heat transfer in thin fibrous materials under high heat flux, Fire Technology 35: 210-231.

4. Li, J.; Tian, M. 2016. Personal thermal protection simulation under diverse wind speeds based on life-size manikin exposed to flash fire, Applied Thermal Engineering 103: 1381-1389. https://doi.org/10.1016/j.applthermaleng.2016.04.155.

5. Wang, Z.; Li, J.; Tian, M. 2015. CFD simulation of flame manikin test for fire proof garment during flash fire exposures and cooling phase, 5th International Conference on Education, Management, Information and Medicine (EMIM).

https://doi.org/10.2991/emim-15.2015.64.

6. Ghazy, A.; Bergstrom, D. J. 2011. Influence of the air gap between protective clothing and skin on clothing performance during flash fire exposure, Heat Mass Transfer 47 (10), 1275-1288. https://doi.org/10.1007/s00231-011-0791-y.

7. Collin, A.; Marchand, A.; Kadi, A. et al. 2015. Study on visible-IR radiative properties of personal protective clothing for firefighting, Fire Safety Journal 71: 9-19. https://doi.org/10.1016/j.firesaf.2014.11.006.

8. Mandal, S.; Song, G. 2014. An empirical analysis of thermal protective performance of fabrics used in protective clothin, Annals of Work Exposures and Health 58(8): 1065-1077. https://doi.org/10.1093/annhyg/meu052.

9. Mandal, S. 2016. Studies of the Thermal Protective Performance of Textile Fabrics used in Firefighters' Clothing under Various Thermal Exposures. PhD thesis, Department of Human Ecology University of Alberta. https://doi.org/10.7939/R32B8VP1R.

10. Tian, M.W.; et al. 2017. Numerical prediction of degree of skin burn in thermal protective garment air-gap humain body system, Thermal Science 21(4): 1813-1819. https://doi.org/10.2298/TSCI160512073T.

11. Dahamni, S.; Benarous, A.; Merzouk, M. 2016. Analysis of heat transfer in a firefighters clothing, National Conference on CFD and Technology (CFD \& Tech), COMENA, Algiers, Algeria.

12. Benchabi, R.; Lanani, A. 2017. Two dimensional numerical simulation of natural convection in a square cavity, Mechanika 23(4): 545-551.

http://dx.doi.org/10.5755/j01.mech.23.4.14482.

13. Collin, A.; Acem, Z. et al. 2013. A Heat transfer study 
for firefighters' protective clothing, $21^{\text {st }}$ French Congress of Mechanics (CFM), Bordeaux, Frensh. https://hal.univ-lorraine.fr/hal-01446042.

14. Eidukynas, V.; Poška, A. J.; Grigas, V. 2015. Dynamics of the large opening fire valves of dust explosions automatic localization systems, Mechanika 21(5): 397403. http://dx.doi.org/10.5755/j01.mech.21.5.11759.

15. Bergman, T. L.; Lavine, A. S. et al. 2007. Fundamentals of Heat and Mass Transfer, Wiley \& Sons Publishing, 6th Edition, NJ, USA. 1070 p.

16. Du, M.-Z. et al. 2016. Numerical modelling of transient heat transfers in microsystem of protective clothing, Thermal Science 20(3): 945-48. https://doi.org/10.2298/TSCI1603945D.

17. Lv, Y. G.; Liu, J. 2007. Effect of transient temperature on thermoreceptor response and thermal sensation, Building and Environment 42: 656-664. https://doi.org/10.1016/j.buildenv.2005.10.030.

18. Ratovoson, D.; Huon, V.; Jourdan, F. 2015. A 3D finite element model for hyperthermia injury of bloodperfused skin, Comput. Methods Biomech. Biomed. Engin. 18(3): 233-242.

https://doi.org/10.1080/10255842.2013.790963.

19. Ostrowski, Z.; Bulinski, P.; Adamczyk, W.; Nowak, A. J. 2015. Modelling and validation of transient heat transfer processes in human skin undergoing local cooling, Prz. Elektrotechniczny 91: 76-79. https://doi.org/10.15199/48.2015.05.20.

20. Onofrei, E.; Petrusic, S.; Bedek, G.; Dupont, D.; Soulat, D. 2013. Study of Heat Transfer Through Multilayer Textile Structure Used in Firefighter Protective Clothing, $13^{\text {th }}$ AUTEX World Textile Conference, Dresden, Germany.

https://www.researchgate.net/publication/256668703.
S. Dahamni, A. Benarous

TOWARDS A THERMAL CHARACTERIZATION OF A FIREFIGHTER'S PROTECTIVE CLOTHING

S u m m a r y

In the present work, an unsteady analysis is carried out for the thermal characterisation of a firefighter protective clothing. Coupled radiative and conduction heat transfers are considered inside the clothing with a focus on the thermal level on the first skin layer. The protective garment is modelled as a 1D solid medium, featuring three layers of tissues, separated by several air-gaps. A parametric analysis is performed in the aim to predict the effect of conductive and radiative tissue's properties fluctuation on the first skin's layer temperature. The thermal balance equations are written in a finite element (FE) formulation and solved using the COMSOL Multiphysics ${ }^{\circledR}$ software. Predictions were provided for the temperature and heat flux distributions in the fabric, skin, and air-gap as a function of time, as well as the time to receive skin burn injuries. The results obtained were compared with stationary 2-D calculations, and faced to unsteady simulations, based on the finite volume method. A $50 \%$ relative reduction in the absorptivity of the skin (in the case of wearing a fine knitted fabric) makes it possible to reduce the surface temperature of the skin to a tolerable value.

Keywords: fire safety, protective clothing, multilayered fabrics, heat transfer.

Received January 18, 2019 Accepted October 14, 2020 